\title{
Potential of Ayurvedic Drugs in Differentiating Neuronal Stem Cells from Human Breast Milk: A Review
}

\author{
Rinki Kumari ${ }^{*}$.
}

${ }^{1}$ Advanced Centre for Traditional and Genomic Medicine, Institute of Medical Science, Banaras Hindu University, UP, India

\begin{abstract}
Recently, Stem cell therapy has revolutionized excellent clinical therapy with the potential of stem cells to differentiate into various cell types and it may help to replace different cell lines of an organism. Frequent, clinical trials are carried out to merge the new scientific stem cell information and techniques with traditional knowledge and plant extracts that may result in less toxic, affordable, and highly available natural alternative therapeutics. Ayurveda, the traditional Indian system of medicine has given great emphasis to the promotion of health. Ayurveda therapies are based on the restoration of body balance and nourishment of dhatus. Rasayana concept of Ayurveda explains tissue regeneration and cell renewal. Rasayana drugs and therapies provide research opportunities for the biology of regeneration. Specific Medhya Rasayana stimulates and nourishes respective Medha (Dhi, Driti, and Smriti) dhatus. Interpretation of this description offers clues for specific differentiation of neuronal stem cells from human breast milk (HBM) in the presence of some herbal extracts. The previous studies suggest that neuronal stem cells differentiate from Human Breast Milk (Human mesenchymal stem cell) more effectively with Madhya Rasayana drugs.

The present review highlights the potential of Ayurveda and its possible contributions in regenerative medicine.
\end{abstract}

Keywords: Human breast milk, Stem cell, mammary gland, nervous system, nestin-positive, non-invasive

*Corresponding Author

Email: rinkiv3@gmail.com

\section{Introduction}

In recent times, stem cell therapy (SCT) is on top position in the clinical area of regenerative therapy and these cells are used with the enormous goal with clinical application in the medical field. These cells also prevent and treat various clinical issues with a unique aspect including Regenerate (self-renewal) \&Repair injured tissues and organs in the organism. The various study declared that these cells have the ability to distinguish into a specific adult cell. Globally, clinical SCT is growing from a strong root and have promising clinical therapeutic setup in an organized form. Definite generated cells and tissues from pluripotent stem cells are grafted on injured tissue to repair along with to regenerate specific tissue or organ [1-2].These cells have the power to make each tissue and organ within the specific frame. Stem cells, able to construct every type of human tissues or organ and due to unlimited self-renewal to produce progeny exactly the same as the originating cell with the extremely regulated mode. Stem cells are also differentiate into different adult specific cell lineages under appropriate clinical conditions [3].Therefore, SCs are geared up to generate a specific cell type that becomes a part of the healthy living system or living organism. Recently, McGinley et al., (2016), defined stem cells are most applicable in clinical field and involved to generate whole organs for organ replacement [4]. Rapidly, these are also involved in treating untreatable neurodegenerative diseases such as Parkinson's disease [5] Alzheimer's disease [4], and diabetes mellitus [6]. The multipotent human stromal cells are categorized as adult stem cells and isolated from adult tissues including bone marrow and various non-marrow tissues like adipose tissue, adult muscle, corneal stroma or the dental pulp of deciduous baby teeth these sources are knows as 
invasive and painful. Other some study have reported that human breast milk is a rich source of multipotent mesenchymal stem cells. Breast milk could be an alternative source of stem cells for autologous stem cell therapy. In addition some clinical waste products such as placenta, umbilical cord blood as well as body or tissue fluids such as synovial fluid amniotic fluid and menstrual blood useful for stem cell isolation. These sources are completely non-invasive and non-pain able to have less ethical issues [2].

Recently, several studies have committed that these cells have the potential to differentiate into a number of cell lineages types including osteoblasts (bone cells), chondrocytes (cartilage cells), myocytes (muscle cells), neurons, glia, tendon-ligament and adipocytes (fat cells which give rise to marrow adipose tissue) etc. with much promise for use in clinical stem cell therapy [7-8].

Human embryonic stem cells (hESCs) are the foremost versatile, consequent from blastocysts (three to five-day recent embryo) that grow from embryo to fetus (ectoderm, mesoderm, and hypoblast are the 3 germ layers).These cells can form any type of cell and tissue within the body; Once stem cells are directed to a particular lineage, they can regenerate cells and tissues as part of normal growth and repair. Although, at this stage, usually, they cannot move away from their dispersed cell type. Adult cells are typically only able to replicate into the precise cell lineage for example- the cells are from - skin cells can only replicate into other skin cells. Therefore, researchers have found ways to induce pluripotency ability to replicate into other cell lines or tissue lineage among some adult cells for possible use in regenerative medicine [9].

Nowadays, hMSCs are being studied more extensively worldwide due to having scientifically verified essential clinical potentials. Joshi and Bonde (2014) have compared studied thath MSCs have some more advantages over embryonic stem cells (hESCs) such as it can simply isolate from different sources and can easily to in vitro culture along with negligible ethical issues allied with their application. Although it has most required alternative significant advantage never recognized as foreign cells once utilized in stem cell therapy in any clinical cases, due to its HLADR (human white corpuscle antigen-antigen D related)-negative characteristic unique feature [10].

Currently, various reports have committed that the research tasks in the field of hMSCs are being excellent experiment and studies; due to its scientifically proven abilities and enormous clinical potential. In addition, hMSCs have some important advantages over embryonic stem cells (hESCs) like easily isolate from different sources; easy to in vitro culture; negligible ethical issues allied with their application. Although several studies have evidence to provide these cells never recognized as foreign cells when used in stem cell therapy in various clinical cases because of their HLA-DR (human leukocyte antigenantigen D related)-negative characteristic [10]. In 2017, Witkowska-Zimny et al., have attempted to provide that human breast milk (hBM) is good for health with high-quality of nutritional and immunological properties. It is recognized as the ideal breastfeeding to infant to improve their health in societies. hBM contains a heterogonous component of immunological, biochemical and cellular properties that have a potential role at the different stage of lactation, the degree of breast fullness, infant feeding and the health of the breastfeeding dyad [11].

Numerous studies have suggested that these components have the potential to significantly enhance the immunity of infants because of the presence of the different components of micro and macronutrients and these components are involved to protect infants from infections (due to containing increased numbers of infectionfighting white blood cells). Additionally, provides nourishment, fortification, and organic process programming to an infant, with short and semipermanent effects [11-13].Moreover, the presence of maternal cells or heterogeneous cells in hBMs (Figure 1), including leukocytes, epithelial cells, lactocytes (milk-secretory cells), and myoepithelial cells (from the ducts and alveoli of 


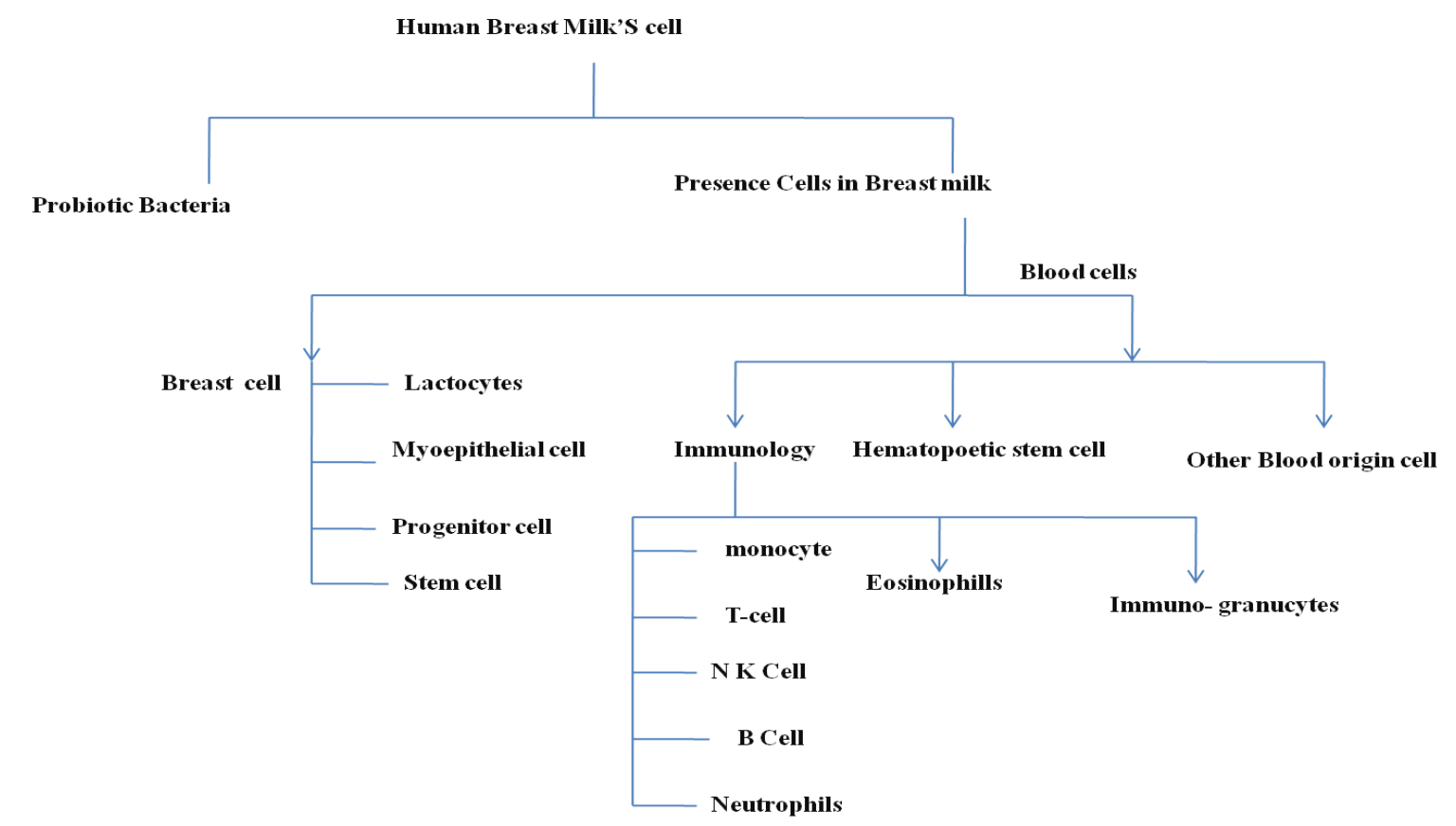

the mammary gland) are involved in various developmental stages of infants.

Figure 1. schismatic presentation of heterogeneous cell in human breast milk

Although, these cells have numerous biomedical application due to heterogeneous nature [11].

Recently, evidence has declared that human breast milk showed positive Nestin, which marked the presence of important cellular components i.e., progenitor/stem cells. Various studies were able to explain the commensal and beneficial bacteria like- lactic acid bacteria and bifidobacteria's presence with good spring, in human breast milk, which is important for the proper development of infants. It is also full of a hierarchy of regenerative and progenitor cells. Therefore, hBM composed dynamic cellular components and is the good proportion of singular cell types which can be altered by various factors [11].

Based on the various evidence, human breast milk has been recognized as a mainly applicable clinical therapeutic agent, and it is a most suited applicable agent like other drug therapy or regenerative medicine [14].

Cregan et al., and his team explained the presence of a protein marker known as neuroectoderm marker (multipotent stem cell marker) such as nestin-positive putative mammary stem cells in hBM. However, it is also a presence in the heterogeneous subpopulation of milk with low frequency. Scientists have reported that nest in showed similar properties of other stem cells. Frequently, expressed in follicle stem cells and also in their differentiated progeny [15]. It has most useful clinical application, to differentiate into different cells and tissues like neural, bone marrow, pancreatic and epithelial cells like hESCs [14-15].

In addition, the presence of cell surface markers like cytokeratin (CK) 5, Hoechst 33342 and nesting are not able to explain the differentiation potential of these mammary cells isolated from human breast milk [14]. Even though, in the mammary gland, stem cells have the capability to regulate program and immediately, alters into the full secretary state during pregnancy and in the postpartum period [16].

Some other researchers have also supported the findings of Cregan et al., that hBM derived stem cells had the capability to differentiate into neural cell lineages as like both embryonic and mesenchymal stem cells. On the basis of other studied that the exposure of the milk cells into neurogenic medium, leads to differentiation into all three essential neural lineages 1) B-tubulin as a neuron marker expressed by neurons, 2) O4 marker expressed by oligodendrocytes, 3) the GFAP marker expressed by astrocytes [17]. 
Hosseini et al., showed that both mammary glands and nervous system, are originated from an embryo. As a result milk cells are a good source of neural cells and involved in the development of the enteric nervous system. It consisting of a mesh-like network of neurons that regulate the function of the gastrointestinal system [17].

Literature search reported that pluripotent stem cells have the ability to generate self-renewing stem cells and presence in hBM. These cells have a specific feature of multi lineage segregation latent for all three germ layers i.e., ectoderm, mesoderm, and endoderm [17].

Various studies confirmed that hBM stem cells are also express classic essential embryonic stem cell surface markers including octamer-binding transcription factor 4 (OCT4), sex determining region Y-box (SOX2), SEEA4, TRA 1-60/81 and homeobox (NANOG). Cell surface markers confirmed that hBM stem cells possibly will perform similar to both embryonic and mesenchymal stem cells [17-18].

Ancient traditional medicinal systems like Ayurveda, Siddha, Unani and also revealed in the ancient Vedas and originated in India. Ayurveda means "science of life" and longevity" that developed between 2500 and 500 BC [19]. From the ancient era, Ayurveda always recommends the entire system to be in this world with a long healthy life. Several pieces of literature expressed that Ayurveda has knowledge and source to the regeneration of cell to treat and cure clinical diseases via uses of the different herbal product. These herbal extract (a single and polyherbal formulation) significantly decrease various clinical disease burden. Although, still, the mechanisms of action of single and polyherbal extracts are mostly unknown [19].

Ayurveda consent with a dynamic exchange in terms of continuous regeneration of Dhatus with the physiological process of Doshas i.e. Vata, Pitta and Kapha. As per modern concept, the tissues undergo constant destruction and regeneration in the body. Ayurveda suggested that several healthy dietary, lifestyle and herbomineral interventions for Dosha balance and
Dhatu nourishment resulting in healthy long life through tradition rehabilitation.

Traditionally rehabilitation such as Panchakarma and Rasayana are used in Ayurveda for rejuvenation of cells. In addition, natural drugs can assist in the management of neurodegenerative disease burden by making the interaction between Tridosha and Triguna in a well-balanced circumstance. Several scientific evidence showed that natural Medhya Rasayana drugs providing Medhya (intellect promoting) effect to improve the memory of the patients [19]. On the basis of current knowledge about human breast milk stem cells and ayurvedic concepts of regeneration, both together have a major contribution to the development of regenerative herbal medicine with an integrative approach in the modern clinical area [19]

Rasayana is Ayurvedic drug branches which refer to rejuvenating therapy and immune modulation. According to Ayurveda, Rasayana therapy or Jarachikitsa are not involved only covers health management but also delay aging or Vayasthapan, by offering treatment of aging through the rejuvenation process. The enhancement of Rasa (essence) is the quit essential quality that all Rasayana medicines possess, ultimately looking to promote health and vigor of the tissues. Rasahasa characteristic tendency to improve the nutritional status of the human body and reduces stress through three basic mechanisms -1.Rasa (nutrient effect) 2.Agni (digestion and metabolism), 3.Srotas (microcirculation and tissue perfusion). However, Rasayana drug is concerned to promote physical and mental health, improve defense mechanisms of the body and enhance life longevity [19].

Recently, several lines of evidence have reported that more than 200 Rasayana drugs are used for a reduced different type of clinical neurodegenerative burden. Due to the presence of various antioxidants active molecules in these herbal drugs. In Ayurveda, Medhya Rasayana is used for the brain and mood disorder treatment and improving the status of medhya issues [1920]. 
Previous evidence has supported that human mesenchymal stromal cells (hMSCs) contain a multi-potent cluster of cells. Frequently, it can be easily isolated from developed tissue like bone marrow, adipose tissue, including medical waste material (umbilical cord, placenta, and human breast milk). Joshi et al., (2014) have shown thath MSCs capable to differentiate into a wide range of cell lineages. Ita has promising potential role to stem cell therapy and this clinical role of MSCs, increasing the demand of MSC technique [2,10]. Different literature search reported regarding presented stem cell therapy and commonly, use of various chemical stimulant compounds including recombinant cytokine, growth factors, stimulate proliferators and involved in the differentiation process for the normal development of cells. Such compounds have two sites of their application in one site necessitate for the regulation of process and another way, associated with various undesirable effects or disadvantages together with toxicity and excessive costs. Therefore, these negative characteristics of chemical agents forced to scientists for search alternative natural product to complete the requirement for normal process and stimulants to be used as growth factors for stem cell proliferation in stem cell therapy [2].However, study exploring the potential and benefits of human breast milk stem cells in the feeding of infants including stem therapy and regenerative medicine. In the present study, we review the effects of alternative medicines either single or mixture, able to promote cell proliferation and differentiation of hMSCs in neuronal lineage, with their underlying mechanisms.

Various literature search regarding alternative medicines or plant-based remedies have been used in traditional medicine practices from many yearsago for reducing a wide range of diseases. Herbal medicines act as a potential promising alternative way of offering substantial improvement of patient conditions via significantly decreased disease symptoms. Although the mechanisms of action of a single and polyherbal form of extracts mostly remain undetermined and under process. The study tries to define the effect of different herbal extracts on stem cells proliferation and differentiation, and along with the effect of cytotoxic, may provide indepth insights into their disease-curing mechanisms [21-22].

Recently, the use of medicinal herbs or herbal preparation has supported new complementary and alternatives source of growth or stimulant factors for the proliferation of stem cell and these herbal medicines are potentially beneficial for treating various clinical challenges. Ayurveda declared, more than a few plants of this formulation, the so-called 'media' plants, possess different properties. These plant extracts have the neuro-protective ability and in vitro studies was proven that decreased induced neurotoxicity, so that can be able to treat various neurodegenerative disorders like Parkinson's disease, and Alzheimer's disease[23-25].

Scientifically, proved that media' plants act as stimulants to proliferate stem cells and fulfill the required number of cell for patient transplantations. For example, Shorearobusta resin, and Yashada bhasma have shown a protective effect in brain and deoxyribonucleic acid (DNA) damage [26] another important Indian common herbal medicine, Phyllanthus emblica, its fruit has effectively involved in reducing DNA damage in brain cells and also improved genomic stability in neurons and astrocytes [27]. In other in vitro study, Phyllanthus emblica inhibiting the activities of hyaluronidase and collagenase type 2 [28].

\section{Effects of medicinal plants as a stimulant on human stem cells proliferation}

In this part of the article, discuss the regarding medicinal plants and their active phytoconstituent show to involve an increasing number of stem cell and differentiation in a specific lineage. Numerous studies have reported that herbal extracts either single orpolyherbal formulation have a positive effect in the increasing number of stem cell, due to containing a plethora of active phytochemicals such as polyphenols and flavonoids. Polyherbalism, in "SarangdharSamhita" has been highlighted as the concept of polyherbal and supported the active 
phytochemicals components of single plants have been well established. Usually, bioactive molecules are present inan individual plant with less amount and insufficient to achieve the desired therapeutic effects. Therefore, a few scientific studies evidence have exposed that combined various plant may produce a more positive effect, due to herb-herb interaction or synergism, as compared to individual use of the plant extract[29-31].

The promising effect of the various parts of medicinal plants including roots, leaves, stem, and fruits, are used in wide range of herbal drug preparations for the treatment of different clinical diseases. In traditional medicine, these plantderived bio-active chemicals are synergistically very useful in treating and curing clinical diseases and also decreasing their symptoms. Different clinical studies elaborate different activity of bio-active chemicals on the endothelial or vascular genesis, angiogenesis, antiadipogenic, osteogenic, neurogenic, and also showed proliferative effects on human mesenchymal stem cells. These studies were confirmed by RNA expression analysis [2]. Curcumin(1E,6E)-1,7-Bis(4-hydroxy-3-methoxy phenyl) hepta-1,6-diene-3,5-dione or diaryl heptanoid,)(figure-2) is a bright yellow phytopolyphenol compound or bioactive molecule and found in flower of Curcuma longa (turmeric), belonging to the family and Zingiberaceae (a member of the ginger) and one of the oldest Indian medicine. It possesses a wide range of pharmacologic properties -anticancer, antioxidant and anti-inflammatory properties. It is also used as an herbal supplement and also in cosmetics ingredient, food coloring and food flavoring. Curcumin is an active biochemical which can be stimulate developmental and adult hippocampal neurogenesis it may enhance neural plasticity along with its repair [32].

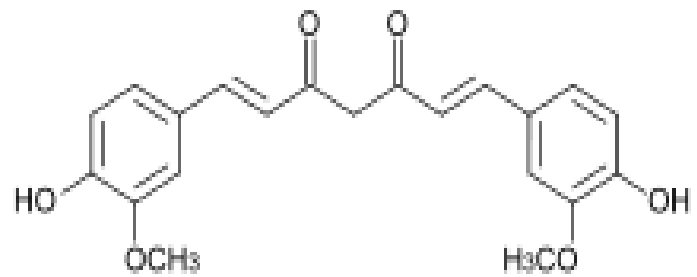

Figure 2. showing curcumin, a linear diarylheptanoid (consist of two aromatic rings (aryl groups) joined by a seven carbons chain (heptane) and having various substituents).

Wang et.al., (2014) showed the neuroprotective effects of diarylheptanoid in animal models through the inhibition of $A \beta$ generation and subsequently, induced autophagy by downregulatingPI3K/Akt/mTOR signaling pathway [33]. Some other studies showed these yellow bioactive molecules exhibited the biphasic effects on the propagation and discrimination of stem cells and also on spinal cord neural progenitor cells and embryonic neural progenitor cells [32,34-35].

Ginkgo biloba is one of the oldest Chinese plant species and possess different tradition medicinal properties like-dementia, eye problems, intermittent claudication, tinnitus, and other health problems including asthma, bronchitis, and kidney and bladder disorders and act as a dietary supplement. It was proven that Ginkgo nuts are members of the royal court for senility. Zhuang et al., showed that Ginkgo extract contains salvianolic acid B (Sal B induces the proliferation of NSPCs) and involved in the proliferation of endogenous neural stem cells in vascular dementia rats. Leaves of Ginkgo (figure3) contains many active molecules like $22-24 \%$ flavonoids and 5-7 \% terpene trilactones (gingolides and bilobalide) and also EGb 761(ginkgolid A, B, C) and bilobalide (EGb 761) and showed neural modulatory. It acts as antitumor, anti-aging, hepato-protective and cardioprotectiveagents [36].

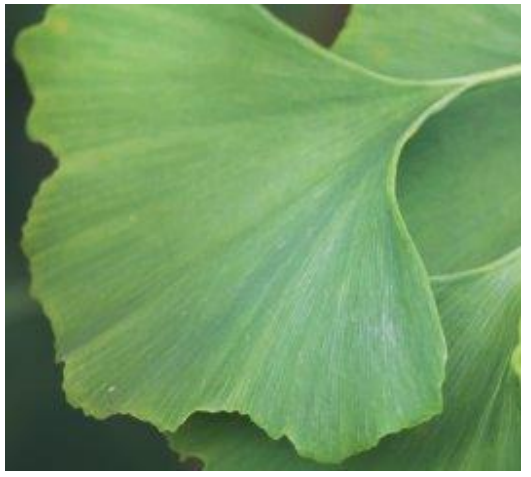

Figure 3 Leave of Ginkgo biloba.

Some recent studies have evidence that this extract involved in the regulation of different neurotransmitter level and capable to strongly inhibit monoamine oxidase A and synaptosomal 
uptake of DA, 5-HT and norepinephrin. A few of other in vitro studies showed this extract can significantly enhance the proliferation of mouse cochlear NSCs and differentiation into functional neurons [37].

Another Chinese medicinal extract, Scutellaria baicalensis Georgi, known as Chinese skullcap (figure-4), is a species of flowering herbs and belonging to the Lamiaceae family, it is also known as a golden herb from the garden of Chinese medicinal plants. It found in many European, East Asian countries, and the Russian Federation. It is frequently used in chine and officially include in Chinese Pharmacopoeia. Its dried root is known as Huang-Qin and used in the preparation of several Chinese herbal medicines. Root has been applied in the treatment of various clinical issues such as diarrhea, dysentery, hypertension, hemorrhaging, insomnia, inflammation and respiratory infections. Scutellaria Baicalensi contains active compound Baicalin (flavonoid) and promotes neural differentiation but inhibits glial formation by regulating expression of stat3 and bHLH in E15-16 embryonic neural precursor cells (NPCs)[38].

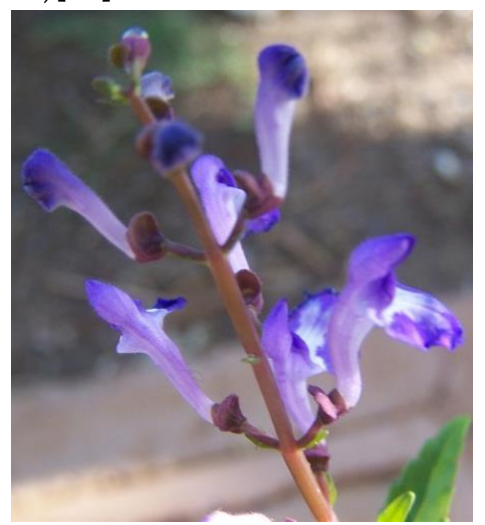

Figure- 4 plant of Chinese skullcap source https://www.flickr.com/photos/salvias/56665 69724.

Carica papaya (figure-5) belong to family Caricaceae and its origin is in the tropics of the Americas, perhaps from southern Mexico and neighboring Central America. The leaves, seeds, roots and unripe pulp of papaya showed different medicinal activity like antidiabetic, antiobesity, antitumor, antimicrobial agents and healing properties. Also involved in the treatment of dengue fever and ulceretic [39].
Other in vitro study the leaf extract up regulated the synthesis of thrombopoiesis related cytokines interleukin-6 and also upregulated stem cell factor by hMSCs, isolated from exfoliated

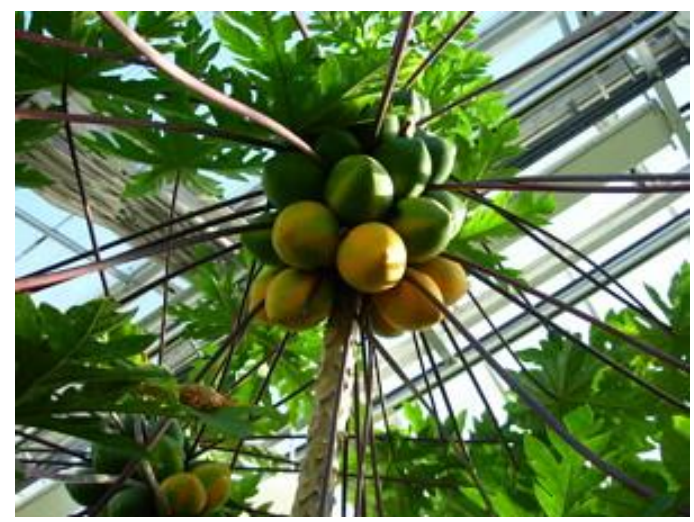

Figure 5 Carica papaya source -

https:// www.flickr.com/photos/plsc100/31730 9400/

deciduous teeth. It has an effect on improving thrombocyte counts in both human and murine models, therefore, C. papaya leaf extract as a precious potential therapeutic agent for clinical diseases [39].

Korean mistletoe, known as Viscum album (European mistletoe), has been traditionally used as a medicinal plant. The extract of the plant contain lectins act as therapeutically active biomolecules and shown to be cytotoxic against tumor cells. The various report as shown proliferative activities on placenta-derived hMSCs. The extract can regulate cytotoxicity on HepG2 cancer cells at low concentrations of 1-5 $\mathrm{pg} / \mathrm{ml}$ but proliferates naive placenta-derived hMSCs by way of autophagy mechanisms [40].In some studies, it can inhibit telomerase activity and result in DNA fragmentation and tumor cell apoptosis[41].

Dhanvantar Kashaya (a decoction of herbs having regeneration property) prepared on the base of the concept of polyherbal formulation (PF). In vitro study, this formulation has regeneration property- on Wharton jelly mesenchymal stem cells (WJMSCs). PF has used as a stimulant - growth enhancer increased the proliferation rate; also decreased the turnover time, and also delayed senescence. It is able to improve the yield and quality of stem cells in vitro 
and act as a non-toxic supplement for the culturing of a cell [42].

Dan-Qi-TongMai-Pian, is Chinese herbs extract namely prepared by combination of Astragalus and Salvia, has shown negative apoptosis of BMderived hMSCs through stimulating c-IAP-1/2 expression and restricting caspase- 3 activation [43].

Ayurveda literature search regarding medicinal plant, in Ayurveda Pharmacopeia, out of 200 Rasayanadrugs, some herbal extracts such as Mucuna gigantean, Angelica Sinensis and Salvia miltiorrhiza are neurogenic and has a specific tissue affinity with specific target action (Gamitva in Ayurveda-'reaching the target'.) in the brain. These remedies have shown much promise in the proliferation and differentiation of hMSCs in neuronal cell differentiation [2]. The effect of these neurogenic medicine on hMSCs are shown to differentiate into neural cells in vitro, confirmed by RNA expression of some neurogenic markers like - epidermal growth factor (EGF) or brain-derived neurotrophic factor (BDNF), some of protein and nestin, a marker of neural precursors [44].

Angelica Sinensis (Danggui) is commonly known as dong quai or "female ginseng" and its familyApiaceae. Its originates in China and grows in cool high altitude mountains like Japan, and Korea. Numerous studies have shown its dried root identified as Radix Angelica Sinensis (RAS) are frequently used in China. It is more effective to treat various clinical disorders - blood deficiency, menstrual disorders such as dysmenorrhea and irregular menstrual cycle and promote blood circulation [45].

Radix Angelica Sinensis (RAS) contain many active chemicals like Ferulic acid, in vitro it can reduce $\beta$-amyloid peptide (induced neurotoxicity\& tau phosphorylation). Other study showed ferulic acid, able to inhibit neurotoxic $\beta$-amyloid peptide aggregation in animal models. Recently, some report showed that higher percentages of neurallike cell differentiation from ADhMSCs compared with hMSCs treated with butylated hydroxyl anisole. It is a commonly used neuronal inducer, act as a stimulant. These finding supported thatferulic acid significantly treat neurodegenerative disorders [45-46].

Mucunagigantea (family Leguminosae) extracts contain active constituent L-DOPA, (act as a precursor for dopamine neurotransmitter). The extract of Mucunagigantea, involved in stem cell therapy specifically nerve-related treatment and also enhances stem cell related treatment capacity.In 2012, Kongos reported that human breast milk-derived hMSCs, when treated with 1 $\%$ acetic acid extract of Mucunagigantea, showed high proliferative properties in neural differentiation. It can also promote up-regulation of mRNA expression of nestin (neural marker) and also $\beta$-III tubulin (an immature neuron marker) [2].

Salvia miltiorrhiza (Chinese or traditional Chinese or pinyin: dānshēn), also known as red sage, Chinese sage, tan shen, or danshen, perennial plant. It belongs to Lamiaceaefamily. Frequently, used in traditional Chinese medicine and native place in China and Japan. Its root extracts differentiating Wharton jelly-derived hMSCs into neural cells with high expression of mRNA nestin, $\beta$-tubulin, neurofilament, and glial fibrillary acidic protein, and showed significant morphological changes. The study was also confirmed by high expression of a neural cell marker i.e., neurite outgrowthpromoting protein [47].

Moringaoleifera (family Moringaceae) is an Indian fast-growing, deciduous plant and widely cultivated for its young seed pods. Its seeds contain many bioactive molecules Morning [4-( $\mathrm{a}-$ L-rhamnosyloxy) benzyl isothiocyanate; GMGITC], is an isothiocyanate. In vitro studies showed isothiocyanate induced PDLSCs toward neural progenitor differentiation. It can increase the expression of neuronal genes, involved in neuron cortical development. Furthermore, moringin are also up regulated genes involved in osteogenesis and adipogenesis [48-49].

Gardenia is a flowering plant (figure-6), belongs to coffee family, Rubiaceae, and its native place are tropical and subtropical regions of Africa, Asia, Madagascar, and Pacific Islands. Its crude extract elevated the numbers of NeuN positive neurons in the hippocampal DG after 8 weeks of 
treatment and increased the surface density of BrdU-positive cells. This extracts act as an antidepressant and promoted neurogenesis in the hippocampus [50].

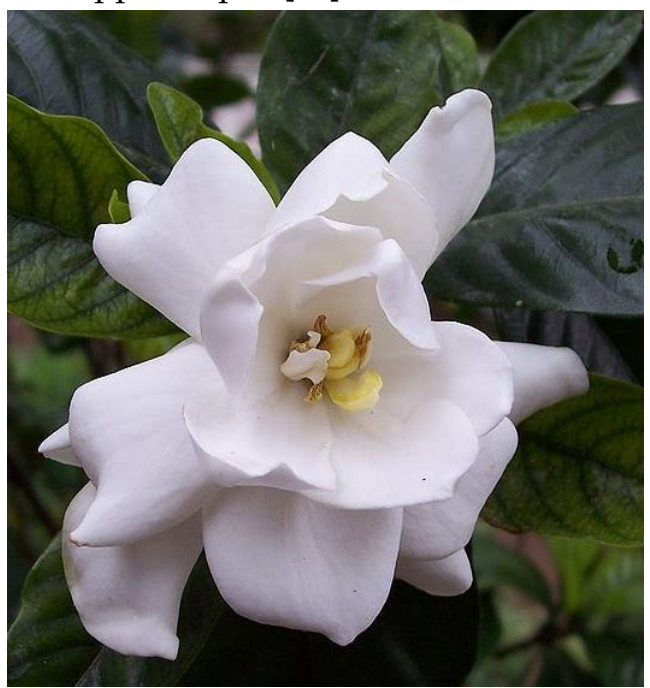

Figure- 6 Flower of Gardenia source https://en.wikipedia.org/wiki/Gardenia

\section{Conclusion}

Stem cell therapy has an enormous positive prospective view in various scientific applications among the presence of ayurvedic stimulating mediator like herbal extract. As known from ancient time herbal drug are trusted medicine for the treatment of disease and reduced their symptoms because of the presence of different active molecules either single compounds or complex combined compounds which act synergetic effect for better therapeutic value. These extracts showed in vitro study the unbelievable positive effect on stem cell differentiation and proliferation still the mechanism of herbal medicine is unknown and modes of action should widely study.

According to the literature reviewed, Stem cell therapy are targeting various neurogenesis and it works for brain repair in different neurodegenerative treatment. As well known, in combination of stem cell with an herbal extract which acts as stimulants have shown amazing finding and provide excellent treatment of clinical issues. Stem cell differentiation into a different specific part like chondrogenic, osteogenic, vasculogenic, neurogenic potential might bevery important for future clinical therapeuticsandgenerated tissue use for replacements in various cases like osteoporosis, heart disease, Parkinson's disease. However, various studies on hMScs derived from clinical waste and human breast milk, are need explored, because these are allied with lessermoral issues rather than other source and associated with the easiest sampling method.

Various literature searches about stimulant, most of the artificial stimulants are associated with major adverse effect and also very expensive rather than herbal extracts. Herbal stimulants showed a great effect on proliferation and differentiation of stem cell in neuron cell growthand cost-effective, highly available, safe alternative source for stem therapeutic application globally.

\section{Competing interests}

The authors declare that they have no competing interests.

\section{Consent for publication}

Not applicable.

\section{Ethics approval and consent to participate}

Not applicable.

Abdollahpour, G: A review on

Leptospirosis. Proceedings of Leptospirosis

Research Conference, Japan, Matsoyamam

;1990: 34- 37

\section{References}

1. Strauer BE, Kornowski R : Stem cell therapy in perspective. Circulation. 2003 107:929-34.

2. Udalamaththa Vindya Lankika, Chanika Dilumi Jayasinghe and Preethi Vidya dagama :Potential role of herbal remedies in stem cell therapy: proliferation and differentiation of human mesenchymal stromal cells. Stem Cell Res Ther. 2016 7:110.

3. National Institutes of Health resource for stem cell research. (2008).The stem cell information Stem Cell Basics page. Available at: http://stemcells.nih.gov/info/basics/ defaultpage.asp

4. McGinley LM, Sims E, Lunn JS, Kashlan ON, Chen KS, Bruno ES, et al: Human cortical neural stem cells expressing insulin-like growth factor-I: a novel cellular therapy for Alzheimer's disease. Stem Cells Transl Med. 2016 5(3):379-91.

5. Roybon L, Christophersen NS, Brundin P, Li JY: Stem cell therapy for Parkinson's disease: 
where do we stand? Cell Tissue Res. 2004 318(1):261-73.

6. Chatterjee S, Davies MJ: Current management of diabetes mellitus and future directions in care. Postgrad Med J. 2015 91(1081):612-21.

7. Ankrum JA, Ong JF, Karp JM: Mesenchymal stem cells: immune evasive, not immune privileged. Nat Biotechnol. 201432 (3): 252-60.

8. Mahla RS: Stem Cells Applications in Regenerative Medicine and Disease Therapeutics. Int J Cell Biol. 2016 2016:6940283..

9. National Institutes of Health: Stem Cell Basics: Introduction. Stem Cell Information 2002.

10. Joshi KS, Bonde R: Insights from Ayurveda for translational stem cell research. J Ayurveda Integr Med. 2014 5(1):4-10.

11. Witkowska-Zimny M, Kaminska-El-Hassan E: Cells of human breast milk. Cell Mol Biol Lett. 2017 22:11.

12. Cristofalo EA, Schanler RJ, Blanco CL, Sullivan S, Trawoeger R, Kiechl-Kohlendorfer $U$ et al: Randomized trial of exclusive human milk versus preterm formula diets in extremely premature infants. J Pediatr. 2013 163(6):15921595.

13. Victora CG, Bahl R, Barros AJD, França GWA, Horton $S$, et al: Breastfeeding in the 21st century: epidemiology, mechanisms, and lifelong effect. Lancet. 2016 387:475-490. .

14. Cregan MD, Fan Y, Appelbee A et al: Identification of nestin-positive putative mammary stem cells in human breastmilk. Cell Tissue Res. 2007 329: 129-36.

15. Fan Y, Seng Chong Y, Choolani MA, Cregan MD, Chan JKY: Unravelling the mystery of stem/progenitor cells in human breast milk. PLoS One. 2010 5(12):e14421.

16. Tiede B, Kang Y: From milk to malignancy: the role of mammary stem cells in development, pregnancy and breast cancer. Cell Res. 2011 21(2):245-257. doi:10.1038/cr.2011.11

17. Hosseini SM, Talaei-Khozani T, Sani M, Owrangi B: Differentiation of human breast-milk stem cells to neural stemcells and neurons. Neurol Res Int. 2014 2014:807896. doi:10.1155/2014/807896.

18. Seymour T, Twigger AJ, Kakulas F: Pluripotency genes and their functions in the normal and aberrant breast and brain. Int J Mol Sci. 2015 16:27288-301.

19. Subhose, P. Srinivas, and A. Narayana: Basic principles of pharmaceutical science in Ayurvěda," Bulletin of the Indian Institute of History of Medicine. 2005 35(2) 83-92.

20. Patwardhan B, Warude D, Pushpangadan P, Bhatt N: Ayurveda and traditional chinese medicine: A comparative overview. Evid Based Complement Alternat Med. 2005 2:465-73.

21. Sehgal N, Gupta A, Valli RK, Joshi SD, Mills JT, Hamel E, et al: Withania somnifera reverses Alzheimer's disease pathologyby enhancing low-density lipoprotein receptor-related proteinin liver. Proc Natl Acad Sci. U S A.2012 109:3510-5.

22. Foster M, Hunter D, Samman S: Evaluation of the nutritional and metabolic effects of Aloe vera. In: Benzie IFF, Wachtel-Galor S, editors. Herbal medicine: biomolecular and clinical aspects. 2nd ed. Boca Raton: CRC Press/Taylor \& Francis; 2011 http://www.ncbi.nlm.nih.gov / books/NBK92765/.Accessed 18 June 2016.

23. Mohandas RKG, Rao MS, Rao GS : Evaluation of amygdaloid neuronal dendritic arborization enhancing effectof Centella asiatica (Linn) fresh leaf. Chin J Integr Med. 2012 1-6. https://doi.org/10.1007/s11655-012-1235-3

24. Kumar GP, Khanum F: Neuroprotective potential of phytochemicals. Pharmacogn Rev. 2012 6(12):81-90. doi:10.4103/0973-7847.99898

25. Chopra A, Saluja M, Tillu G, Sarmukkaddam S, Venugopalan A,Narsimulu G, et al.: Ayurvedic medicine offers a good alternative to glucosamine and celecoxib in the treatment of symptomatic knee osteoarthritis: A randomized, double-blind, controlled equivalence drug trial. Rheumatology (Oxford). 2013 52:1408-17.

26. Datta HS, Mitra SK, Patwardhan B: Wound healing activity of topical application forms based on ayurveda. Evid Based Complement Alternat Med. 2011 134-378.

27. Swain U, Sindhu KK, Boda U, Pothani S, Giridharan NV, Raghunath M, et al: Studies on the molecular correlates ofgenomic stability in rat brain cells following Amalakirasayana therapy. Mech Ageing Dev.2012 33:112-7

28. Sumantran VN, Kulkarni A, Chandwaskar R, Harsulkar A, Patwardhan B, Chopra A et al: Chondroprotective Potential of Fruit Extracts of Phyllanthus emblica in Osteoarthritis. Evid Based Complement Alternat Med. 2008 5(3):329335. doi:10.1093/ecam/nem030

29. Jayakumar RV: Herbal medicine for type?2 diabetes. Int J Diabetes Dev Ctries. 2010 30:111-2.

30. Parasuraman S, Kumar EP, Kumar A, Emerson SF: Antihyperlipidemic effect of triglize, a polyherbal formulation. Int J Pharm Pharm Sci. 2010 2:118-22.

31. Srivastava S, Lal VK, Pant KK: Polyherbal formulations based on Indian medicinal plants as antidiabetic phytotherapeutics. Phytopharmacol. 2013 2:1-15.

32. Kim SJ, Son TG, Park HR, Park M, Kim MS, Kim HS, et al: Curcumin stimulates proliferation of embryonic neural progenitor cells and neurogenesis in the adult hippocampus. J Biol Chem. 2008 283:14497-505.

33. Wang, X., J. R. Kim, S. B. Lee, Y. J. Kim, M. Y. Jung, H. W. Kwon, Y. J. Ahn: Effects of curcuminoids identified in rhizomes of Curcuma longa on BACE-1 inhibitory and behavioral activity and lifespan of Alzheimer's disease Drosophila models. BMC Complement 
Altern Med. 2014 14: 88. doi: 10.1186/1472-688214-88.,

34. Noisa P, Raivio T, Cui W: Neural Progenitor Cells Derived from Human Embryonic Stem Cells as an Origin of Dopaminergic Neurons. Stem Cells Int. 2015 2015:647437. doi:10.1155/2015/647437

35. Kim D.-S., Lee J. S., Leem J. W., et al: Robust enhancement of neural differentiation from human ES and iPS cells regardless of their innate difference in differentiation propensity. Stem Cell Reviews and Reports. 2010 6(2):270281.

36. Zhuang P, Zhang Y, Cui G, Bian Y, Zhang M, Zhang J, et al:Direct stimulation of adult neural stem/progenitor cells in vitro and neurogenesis in vivo by salvianolic acid B. PLoS One. 2012 27:e35636

37. Wang J, Chen W, Wang Y:A ginkgo biloba extract promotes proliferation of endogenous neural stem cells in vascular dementia rats. Neural Regen Res. 2013 8(18):1655-1662. doi:10.3969/j.issn.1673-5374.2013.18.003

38. Li J, Wei T, Zhang QS, et al: Effect of ginkgo biloba extract on spatial learning, memory and expression of hippocampal NMDA receptor-1 subunit in rats with vascular dementia. Shenjing Jiepouxue Zazhi. 2012 28(6):621-626.

39. Aziz J, Abu Kassim NL, Kasim ANH, Haque N, Rahman MT. Carica papaya induces in vitro thrombopoietic cytokines secretion by mesenchymal stem cells and haematopoietic cells. BMC Complement Altern Med. 2015 doi:10.1186/s12906-015-0749-6.

40. Choi JH, Lyu SY, Lee HJ, Jung J, Park WB, Kim GJ: Korean mistletoe lectin regulates selfrenewal of placenta-derived mesenchymal stem cells viaautophagic mechanisms. Cell Prolif. 2012 45(5):420-9.

41. Lee-Yong Khil, Wi Kim, Suyun Lyu, Won Bong Park, Ji-Won Yoon, Hee-Sook Jun: Mechanisms involved in Korean mistletoe lectin-induced apoptosis of cancer cells. World J Gastroenterol. 2007 13(20): 2811-2818.

42. Warrier SR, Haridas N, Balasubramanian S, Jalisatgi A, Bhonde R, Dharmarajan A: A synthetic formulation, Dhanwantharam kashaya, delays senescence in stem cells. Cell Prolif. 2013 46:283-90.

43. Yang L, Sun HY, Sun T, Qi NM: The research progress of MSCs proliferation and differentiation in bone injury according to the TCM theory. Afr J Biotechnol. 2009 8(4):524-528, 1.

44. Moore TJ, Abrahamse H: Neuronal Differentiation of Adipose Derived Stem Cells: Progress So Far In J Photoenergy. 2014 Article ID 827540 .
45. Wu YC, Hsieh CL:Pharmacological effects of Radix Angelica Sinensis (Danggui) on cerebral infarction. Chin Med. 2011: 6:32.

46. Sgarbossa A, Giacomazza D, di Carlo M: Ferulic acid: a hope for Alzheimer's disease therapy from plants. Nutrients. 2015 7(7):5764-82.

47. Ma L, Feng XY, Cui BL, Law F, Jiang XW, Yang LY, et al:Human umbilical cord Wharton's Jellyderived mesenchymal stem cells differentiation intonerve-like cells. Chin Med J. 2005 118(23):1987-93.

48. Brunelli, D. et al:Te isothiocyanate produced from glucomoringin inhibits NF-kB and reduces myeloma growth in nude mice in vivo. Biochem Pharmacol. 2010 79:1141-1148.

49. Letizia R , Diomede F, Gugliandolo A, Scionti D, Giudice FL, Cariccio VL, et al.: Moringin Induces Neural Diferentiation in the Stem Cell of the Human Periodontal Ligament. Scientific Reports. 2018 8:9153.

50. Yu Y, He J, Zhang Y, Luo H, Zhu S, Yang Y, et al.: Increased hippocampal neurogenesis in the progressive stage of Alzheimer's disease phenotype in an APP/PS1 double transgenic mouse model. Hippocampus.2009 19(12):1247-53. 